\title{
SIMULAÇÃO DINÂMICA PARA ANÁLISE DE CONFIABILIDADE DE UM PROCESSO DE BENEFICIAMENTO DE MINÉRIO DE FERRO*
}

\section{Resumo}

Rodrigo Cesar de Miranda ${ }^{1}$ Klaydison Carlaile SIlva² Mônica Guimarães Vieira ${ }^{3}$ Alex Holtzapple ${ }^{4}$

A importância de descrever o processo de beneficiamento por um modelo matemático tem sido apresentada por vários pesquisadores. O principal benefício é o controle e a otimização do processo dentro de uma situação industrial. O modelo seria capaz de prever determinada variável de controle do processo a partir de dados conhecidos. Assim, a simulação dinâmica representa um marco no campo da otimização de processos minerais. Essa tecnologia de simulação tem uma ampla aplicação no estudo de processos, o que permite a obtenção do seu conhecimento e domínio operacional. Além disso, possibilita melhores definições nas etapas de projeto, além de realizar uma análise de confiabilidade mais realista. $O$ presente trabalho consiste em realizar uma análise de confiabilidade, através da simulação dinâmica, para entender como as paradas não-programadas influenciam a produção de uma planta de beneficiamento de ferro. Ainda, visa entender o desempenho fenomenológico dos equipamentos de acordo com a entrada de diferentes tipos de minérios e também como são suscetíveis a condições climáticas.

Palavras-chave: Simulação dinâmica; Análise de confiabilidade; Lógica escada; Hematita e canga.

\section{DYNAMIC SIMULATION FOR RELIABILITY ANALYSIS OF AN IRON ORE BENEFICIATION PROCESS}

\section{Abstract}

The importance of describing the beneficiation process by a mathematical model has been presented by several researchers. The main benefit is the control and process optimization in an industrial situation. The model was able to predict certain process control variable from known data. Thus, the dynamic simulation represents a milestone in the field of optimization of mineral processes. This simulation technology has a wide application in the study of processes which allows obtaining the operational field and his knowledge. It also enables better definitions in the design stages, in addition to performing a more realistic reliability analysis. This work is to conduct a reliability analysis through dynamic simulation to understand how non-scheduled shutdowns influence the production of an iron beneficiation plant. Further, it aims to understand the phenomenological performance of the equipment according to the input of different types of metals as well as are susceptible to weather conditions.

Keywords: Dynamic simulation; Reliability analysis; Ladder logic; Hematite and sarong.

1 Engenharia Química, Mestre, Engenheiro Master, B-Right, Optimus Engenharia, Belo Horizonte, Minas Gerais e Brasil.

2 Engenharia de Minas, Mestre, Engenheiro Master, Desenvolvimento de Processos de Tratamento de Minério de Ferro, Vale, Belo Horizonte, Minas Gerais e Brasil.

3 Engenharia Química, Bacharel, Engenheira de Processos, Insight, Optimus Engenharia, Belo Horizonte, Minas Gerais e Brasil.

4 Engenharia metalurgia, Bacharel, Engenheiro de Processos Master, AHConsult, Belo Horizonte, Minas Gerais e Brasil. 


\section{INTRODUÇÃO}

O beneficiamento mineral é definido como o conjunto de operações aplicadas aos bens minerais que visa modificar a granulometria, a concentração relativa das espécies ou a forma, porém sem modificar sua identidade física ou química [1]. Esse beneficiamento é usualmente complexo, devido à diversidade de espécies presentes no minério e aos baixos teores do mineral de interesse. Deste modo, etapas de concentração são comumente necessárias para melhor aproveitamento econômico da mineração.

A importância de descrever o processo de beneficiamento por um modelo matemático tem sido apresentada por vários pesquisadores [2]. O principal benefício é o controle e a otimização do processo dentro de uma situação industrial. O modelo seria capaz de prever determinada variável de controle do processo a partir de dados conhecidos. Assim, o controlador, humano ou inteligência computacional, pode ser capaz de melhorar o desempenho do processo mediante a alteração das variáveis manipuladas. Outro benefício é o de facilitar o desenvolvimento dos projetos de engenharia. Em um típico projeto de engenharia, muitos testes de laboratório são necessários e scale-up desses testes são então realizados. Com o modelo matemático pode-se contornar a imprecisão do scale-up e reduzir a quantidade dos testes de laboratório de flotação [3].

A simulação dinâmica representa um marco no campo da otimização de processos minerais. Essa tecnologia de simulação tem uma ampla aplicação no estudo de processos, o que permite a obtenção do seu conhecimento e domínio operacional. A possibilidade de simular, através de inferências estatísticas, a variabilidade natural da planta, conduz a resultados que mostram todo o horizonte de operação. Também, podem ser alterados parâmetros que evidenciam a eficiência dos equipamentos, demonstrando seu desgaste com o tempo e até mesmo a retomada de valores normais, após uma parada de manutenção [4].

Além disso, viabiliza a avaliação no tempo dos custos de operação, a lucratividade da planta, a interação entre os equipamentos, disponibilidade pelas paradas programadas e emergenciais, entre outros. Isso permite melhores definições nas etapas de projeto, além de realizar uma análise de confiabilidade mais realista. Até mesmo prever como o break even point pode ser alterado com mudanças econômicas do cenário planejado.

O presente trabalho consiste em realizar uma análise de confiabilidade, através da simulação dinâmica, para entender como as paradas não-programadas influenciam a produção de uma planta de beneficiamento de ferro. Além disso, visa entender o desempenho fenomenológico dos equipamentos de acordo com a entrada de diferentes tipos de minérios e também como são suscetíveis a condições climáticas. Para tal, utilizou-se o METSIM $^{\circledR}$ como plataforma de simulação dinâmica de processos.

\section{MATERIAIS E MÉTODOS}

Para realizar a simulação, foram coletados dados históricos da operação da planta em diferentes condições climáticas e com diferentes mineralogias. Como condições climáticas, foram consideradas essencialmente de dois tipos, chuvoso e seco. E sua mineralogia foi classificada como canga e hematita. A canga trata-se de um mineral mais pobre em ferro e que causa problemas operacionais por sua característica argilosa. 
Esses dados foram submetidos a tratamento estatístico, com respeito à ocorrência de falhas. Nesta análise foi considerado todo o universo de falhas. A partir das taxas de falhas são desenvolvidos modelos que levam em conta as redundâncias próprias do projeto analisado e suas propriedades de tolerância a falhas, sendo possível a avaliação dos tempos de reparo, TR, e tempos médios entre falhas, TEF [5].

Além disso, esses dados também permitiram calibrar os modelos fenomenológicos dos equipamentos e seus respectivos desempenhos nas diferentes condições operacionais. Em seguida, foi desenvolvida a simulação dinâmica do processo. Para tanto, criou-se um modelo completo de todo o processo de beneficiamento da planta (Figura 1). Para representar essa complexa indústria, foram modeladas as áreas de mineração, na qual se busca simular o ROM obtido das frentes de lavras; as britagens primárias, secundárias e terciárias; os peneiramentos primários e secundários; e os pátios de pilhas de regularização e o de embarque.

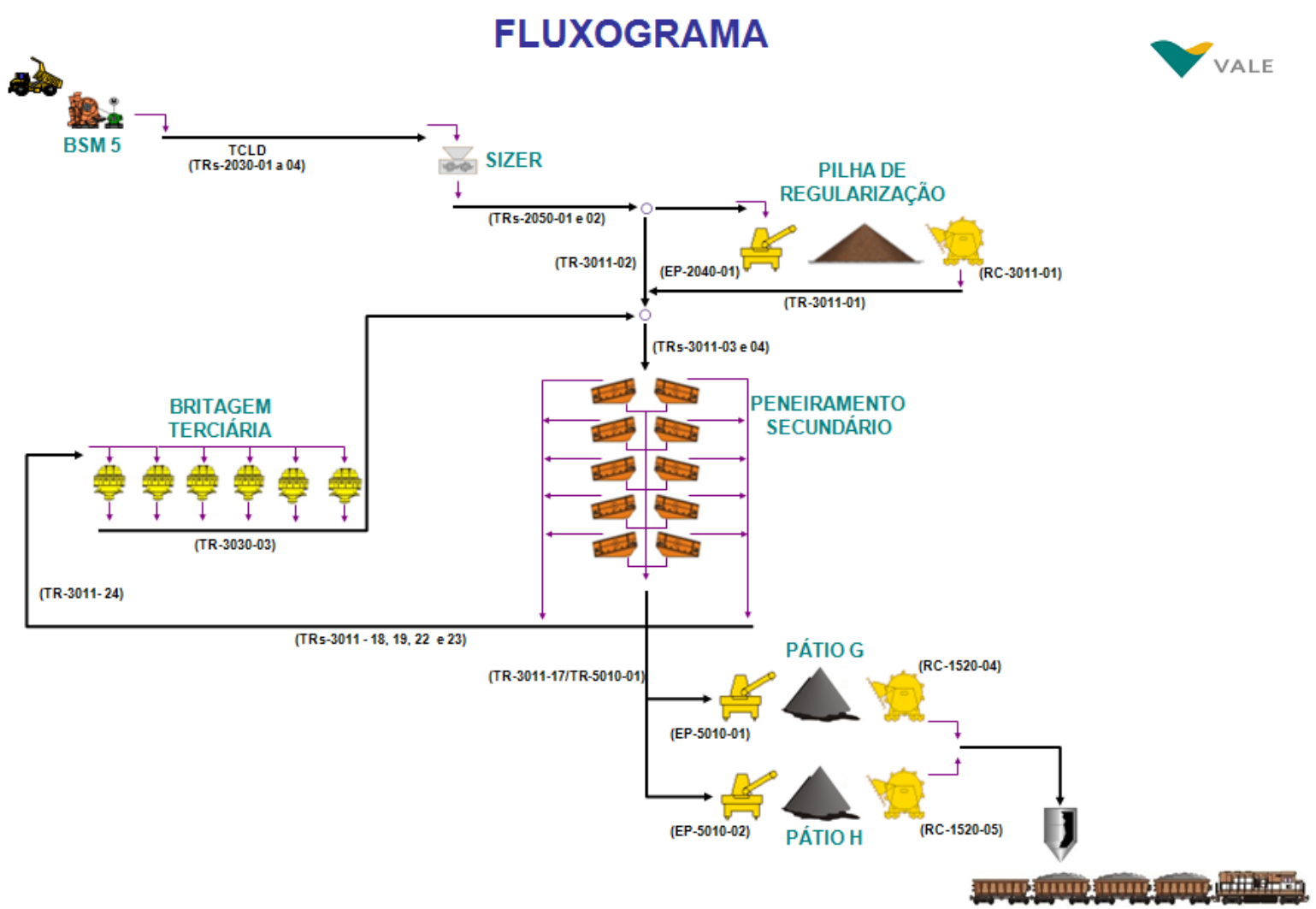

Figura 1. Fluxograma simplificado do processo.

A simulação foi conduzida de forma que a planta fosse alimentada com o material de acordo com o banco de dados. Deste modo, foi utilizada uma taxa de alimentação média em cada mês tal qual a realidade, bem como a porcentagem de canga alimentada apresentada. Também como dados de entrada, foram utilizadas as capacidades de equipamentos presentes e dados de capacidades de armazenamento.

\subsection{Plataforma de Simulação}

Foi utilizado, durante o desenvolvimento desse trabalho, o software comercial METSIM ${ }^{\circledR}$. Esta é uma aplicação computadorizada e programada em APL, que 
permite avaliar modelos aplicados a sistemas de processos, concebidos pelo seu usuário. Aplica o método sequencial modular, no qual envolve a execução do fluxograma do processo como um grupo de unidades de processo para cada um dos quais existe sub-rotinas de cálculo ou módulos [6].

O METSIM ${ }^{\circledR}$ originou-se como um programa de simulação de processo metalúrgico, escrito para realizar balanços de massa para as principais operações unitárias. Desenvolveu-se para um sistema de simulação de processos de uso geral projetado para auxiliar o engenheiro na realização de balanços de massa e energia de complexos fluxogramas de processo. É capaz de simular, com precisão, uma enorme gama de processos envolvendo reações químicas inorgânicas, cominuição, hidrometalurgia, pirometalurgia, energias alternativas e processos fortemente afetados pelas condições ambientais [7].

Apesar de existirem simuladores consolidados em processos e outros em eventos discretos, raríssimo são os simuladores que lidam com ambos. Muitas vezes as indústrias que convivem com os dois tipos de problema acabam utilizando uma destas ferramentas e adaptam suas funcionalidades para representar o aspecto faltante. Já o METSIM ${ }^{\circledR}$ engloba os dois aspectos, inclusive um pode influenciar o outro.

Atualmente, mais de 620 empresas e universidades em 54 países utilizam o METSIM ${ }^{\circledR}$ para projetos, simulação e operação de sistemas de lixiviação, plantas metalúrgicas, bacias de rejeitos, fábricas de fertilizantes, processos ambientais, entre outros [7].

\section{RESULTADOS E DISCUSSÃO}

O modelo matemático desenvolvido, utilizando a plataforma METSIM ${ }^{\circledR}$, representou de forma satisfatória o comportamento da planta industrial. A Figura 2 apresenta duas visualizações do modelo, que expõe o peneiramento secundário e o pátio de embarque.
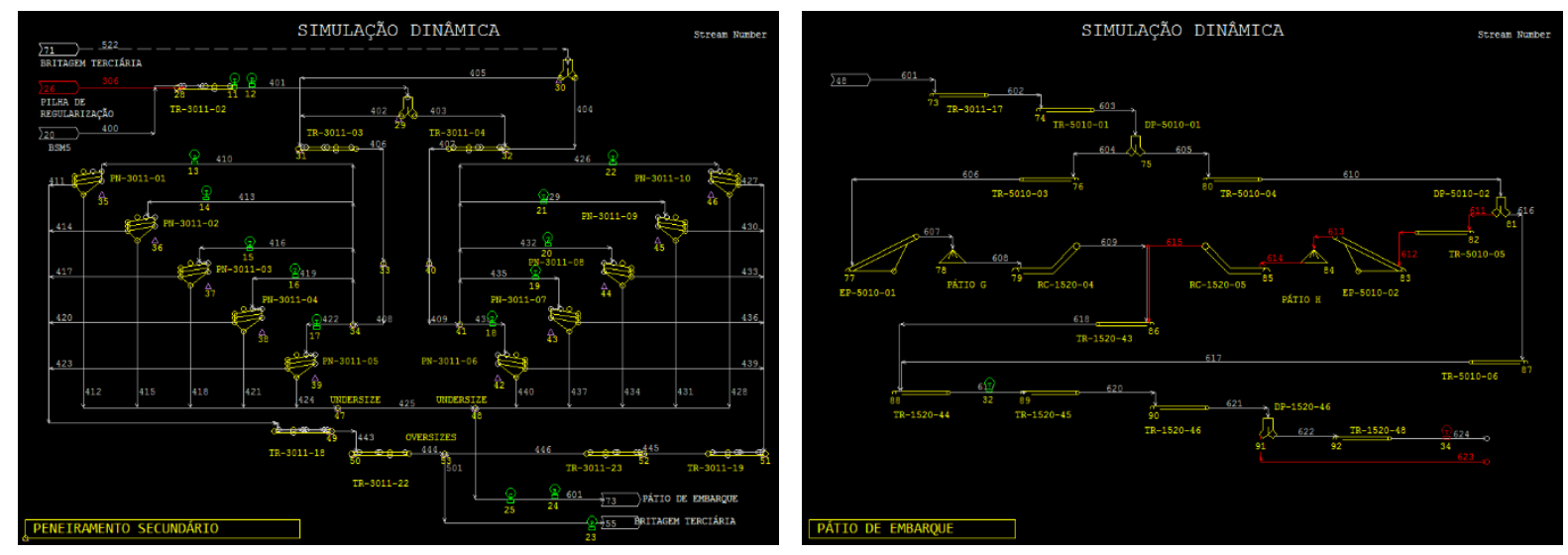

Figura 2. Telas do METSIM ${ }^{\circledR}$ apresentando o peneiramento secundário e o pátio de embarque.

A complexidade desse modelo se deve a necessidade de simular o desempenho de cada equipamento, com suas respectivas ocorrências de falhas. Além disso, utilizar a lógica escada em situações de paradas sequencias dos equipamentos, e assim ter uma maior representatividade do processo.

Ressalta-se a redução no tempo de realização do projeto devido ao uso de uma ferramenta que consegue lidar com os aspectos de modelagem de processos minerais e, simultaneamente, com os eventos de paradas e intertravamento de equipamentos. 
O resultado da simulação foi comparado com os dados amostrados, e o balanço de massa já existente. Além disso, esse resultado também foi verificado pelo engenheiro de processo responsável, que validou os fluxos calculados.

Observou-se que a eficiência dos britadores diminui em $10 \%$ de acordo com a entrada de canga ou hematita. $E$ também como as peneiras são suscetíveis a condições de clima seco e chuvoso, sendo que ocorre uma redução de cerca de $15 \%$.

A Figura 3 apresenta um gráfico de barras com todos os equipamentos da unidade operacional e suas disponibilidades. Fica evidente que grande parte das paradas dos equipamentos são influenciados pela interação da lógica escada, o que limita a disponibilidade da planta.

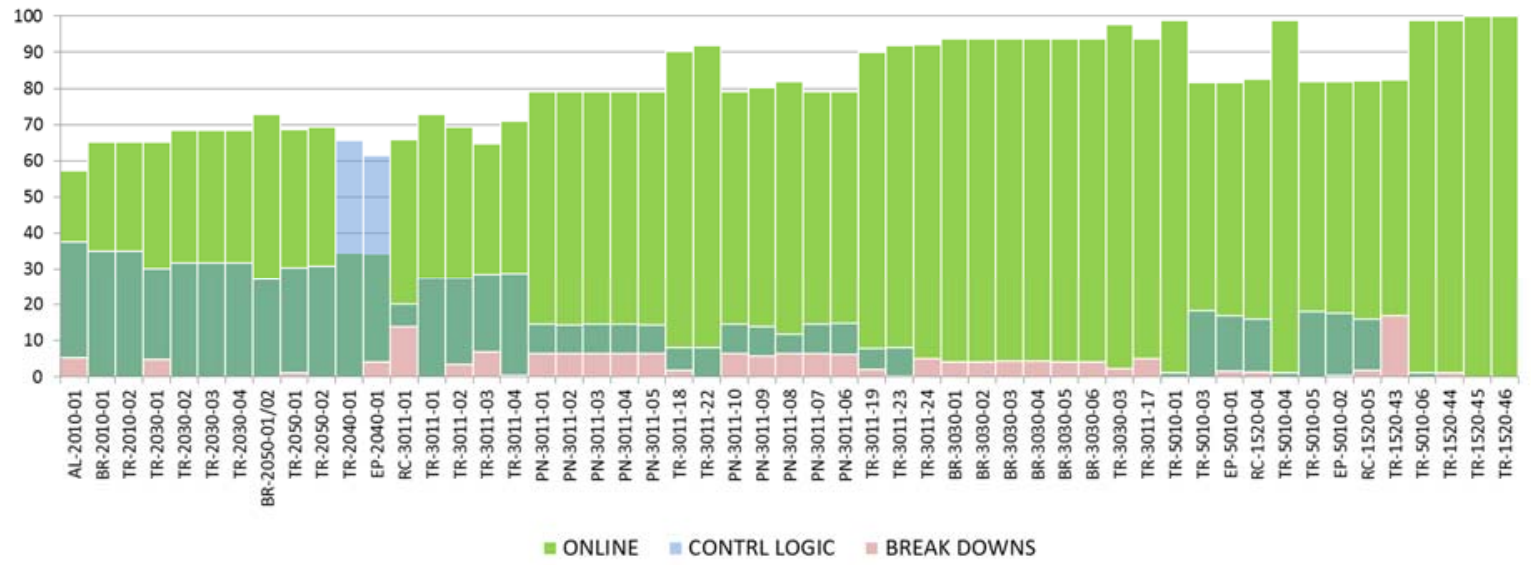

Figura 3. Disponibilidade dos equipamentos.

Através da análise do Percentil 95\%, na Figura 4 observa-se como principais gargalos as correias que enviam a carga circulante para os britadores terciários, sendo essas correias as TR-3011-18, TR-3011-19, TR-3011-22 e TR-3011-23, juntamente com a TR-3011-24.

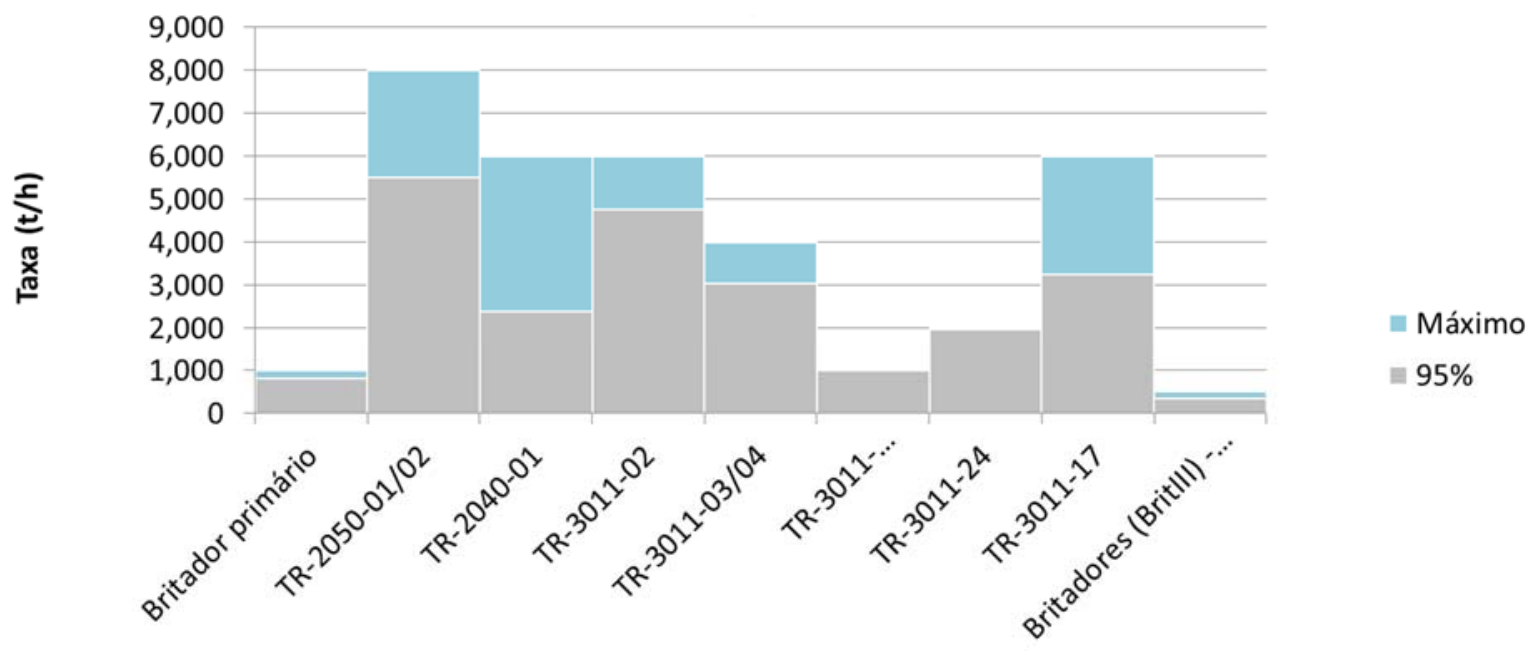

Figura 4. Gargalos identificados. 


\section{CONCLUSÃO}

Aplicou-se simulação dinâmica a uma usina de beneficiamento de minério de ferro para entender como as paradas não programadas influenciam a produção da planta. Identificaram-se como principais gargalos as correias transportadoras que enviam a carga circulante para os britadores terciários. Além disto, observou-se como o desempenho dos britadores muda de acordo com a entrada de canga ou hematita, assim como as peneiras são suscetíveis a condições de clima seco ou chuvoso. Os resultados permitiram uma visão sistêmica da planta de beneficiamento desde a mina até a saída do produto final.

Em termos projeto, através dessa metodologia, conseguiu-se agregar em um estudo a análise da simulação dinâmica e de eventos discretos. Esse estudo fica mais rigoroso com a realidade, pois incorpora a influência tanto de um quanto de outro na simulação.

\section{Agradecimentos}

Agradecemos a Vale por ter permitido publicar esse estudo por simulação dinâmica, no qual se construiu um modelo matemático espelhado em dados amostrados na planta industrial.

\section{REFERÊNCIAS}

1 Luz A B, Sampaio J A, Almeida S L M, editores. Tratamento de Minérios. $5^{\mathrm{a}}$ ed. rev. ampl. Rio de Janeiro: CETEM/MCT, 2010.

2 Fichera M A, Chudacek M W. Batch Cell Flotation Models - A Review. Minerals Engineering 1992; 5 (1), 41-55.

3 Sherrell I M. Development of a Flotation Rate Equation from First Principles under Turbulent Flow Conditions. [Tese de Doutorado]. Virginia Polytechnic Institute and State University, Virginia; 2004.

4 Martins M A S, Miranda R C, Carvalho F J S. Simulação Dinâmica para Verificação dos Ganhos com a Implantação de Controle Avançado de Processo para um Processo de Separação Magnética. In: $39^{\circ}$ Seminário de Redução de Minério de Ferro e MatériasPrimas; 2009 Nov 22-26, Ouro Preto, Brasil.

5 Fogliatto F S, Ribeiro J L D. Confiabilidade e Manutenção Industrial. Elsevier, 2009.

6 Montero R G A. Estudio de Actualización del Balance de Masa para la Simulación del Proceso de Refinación de Ferro-Níquel en Horno Cuchara de Cerromatoso S.A. Empleando METSIM ${ }^{\circledR}$. [Dissertação de Mestrado] Universidad Industrial de Santander, Bucaramanga; 2010.

7 METSIM - The Premier Steady-State \& Dynamic Process [cited 2015 Abr 27]. Available from: http://www.metsim.com/ 